\title{
Antifungal Property of Denture Cleansers and Turbinaria conoides against Candida albicans: A Review Article
}

\author{
Varsha Ravichandran ${ }^{1}$, Shivasakthy Manivasakan ${ }^{2}$, David W Livingstone ${ }^{3}$, Jenie Rosna Albert ${ }^{4}$
}

\begin{abstract}
One of the major problems faced by most of the denture wearers especially geriatric population comes in the form of denture stomatitis, and the common causative organism is found to be Candida albicans. It has the greatest ability to form biofilm on the surface of the dentures. Various mechanical and chemical methodologies have been employed to eradicate this problem. Several studies have evaluated the antifungal properties of commercially available denture cleansers and other novel agents. Turbinaria conoides proves to have promising antifungal properties, and further studies have to be conducted to reach the depth of the individual compound responsible for the antifungal activity.

Keywords: Antifungal, Candida albicans, Denture cleanser, Fittydent, Turbinaria conoides.

Journal of Scientific Dentistry (2020): 10.5005/jp-journals-10083-0927
\end{abstract}

\section{INTRODUCTION}

Most of the geriatric population are denture wearers, but cleansing these dentures is not easy for the geriatric population. Candida very easily adheres to the denture base materials and acts as a hotbed for mitotic stomatitis. ${ }^{1}$ The biofilm produced by the oral flora can cause an inflammatory reaction in denture bearing mucosa leading to denture stomatitis and is seen in $11-67 \%$ of the denture wearers. ${ }^{2}$ The most common site for the denture stomatitis is found to be the palatal mucosa. ${ }^{3}$ Though denture stomatitis has a multifactorial etiology, Candida is found to be the most common factor and has the greatest ability of forming biofilms on the surface of the denture. ${ }^{2}$ Treating the denture stomatitis caused by Candida albicans can be quite challenging as it has a multifactorial etiology. Oral hygiene maintenance and denture cleansing are preventive measures, whereas usage of antifungal drugs is the therapeutic approach. ${ }^{4}$ Dentures can be cleaned either mechanically, chemically, or by combining both the methods. Mechanical cleaning refers to brushing and can be effective if carried out properly, but it may also cause abrasion on the surface of the denture. The commonly prescribed alternative for mechanical methods is a chemical method, which is very simple to use, effective, and reduces the formation of biofilms. ${ }^{5}$ Seaweed extract for medical and pharmaceutical purposes is being used in increased frequency lately. They contain various bioactive compounds, which have antibacterial, antiviral, antifungal, and antihelminthic properties. ${ }^{6}$ Turbinaria conoides seaweed extract has been proven to be effective against Candida albicans. This article is a review on the antifungal property of Turbinaria conoides and denture cleansers against Candida albicans.

\section{Candida albicans}

Candida albicans is generally found on the oral mucosa and epithelial surface of the skin as commensals. ${ }^{2}$ However when the immune system is compromised or the mucosal barriers are broken, it may lead to candidal infection. ${ }^{3}$ The most common types of
${ }^{1-4}$ Department of Prosthodontics and Crown and Bridge, Indira Gandhi Institute of Dental Sciences, Sri Balaji Vidyapeeth, Puducherry, India

Corresponding Author: Varsha Ravichandran, Department of Prosthodontics and Crown and Bridge, Indira Gandhi Institute of Dental Sciences, Sri Balaji Vidyapeeth, Puducherry, India, Phone: +91 9047049915, e-mail: varsha95chandran@gmail.com

How to cite this article: Ravichandran V, Manivasakan S, Livingstone DW, Albert JR. Antifungal Property of Denture Cleansers and Turbinaria conoides against Candida albicans: A Review Article. J Sci Dent 2020;10(2):51-54.

Source of support: Nil

Conflict of interest: None

infection resulting from candidal overgrowth are denture stomatitis and dental caries. ${ }^{2}$ Chronic atrophic candidiasis is also known as denture stomatitis and is a form of oral candidiasis. ${ }^{7}$

An important virulent factor of Candida albicans is adhesion to synthetic PMMA or surface of normal tissues. This adhesion is due to a lectin-like component which is assisted by the hydrophobicity of Candida albicans. ${ }^{2}$ The other virulent factors are protection against host defense mechanism, production of proteolytic enzymes, and phenotype switching. These are related to the rate of colonization and pathogenesis of Candida. ${ }^{8}$ The factors that play a role in the development of stomatitis by Candida albicans are the presence of sugar, decreased level of saliva and oxygen, and type of denture. ${ }^{2}$

Cleaning of dentures is difficult for the elderly people which could cause denture stomatitis further leading to traumatized or irritated tissues. ${ }^{3}$ The most common organism seen in cultures of patients with denture stomatitis was found to be Candida albicans. There was greater adhesion of Candida albicans on rougher denture surface than the smooth surface. ${ }^{1}$

In denture wearers, candidiasis has been found in the tissuefitting surface of a maxillary denture which serves a reservoir of microorganisms. ${ }^{7}$ The most common site it involves is found to be the denture bearing palatal mucosa. ${ }^{3}$

(0) The Author(s). 2020 Open Access This article is distributed under the terms of the Creative Commons Attribution 4.0 International License (https://creativecommons. org/licenses/by-nc/4.0/), which permits unrestricted use, distribution, and non-commercial reproduction in any medium, provided you give appropriate credit to the original author(s) and the source, provide a link to the Creative Commons license, and indicate if changes were made. The Creative Commons Public Domain Dedication waiver (http://creativecommons.org/publicdomain/zero/1.0/) applies to the data made available in this article, unless otherwise stated. 


\section{Biofilm Formation}

Candida species are able to form biofilms on denture surfaces. ${ }^{8}$ Candida species and oral bacterial flora can form a biofilm on the surface of the denture and cause denture stomatitis leading to malfunction of the device. The mucosal inflammation produced by the biofilm can cause a negative impact on the patient's ability to eat and speak. This mixed-species biofilm has bacterial organisms which can cause dental caries and stomatitis and rarely lead to severe pathologies like endocarditis and pneumonia. ${ }^{9}$ Biofilm formation is the first and the most important stage in the pathogenesis of dental stomatitis. ${ }^{8}$ The eradication of these biofilms is very difficult as they possess inherent resistance to both host defenses and therapeutic treatment. ${ }^{9}$

\section{Treatment}

Superficial mycosis such as oral candidiasis is treated with antifungal azoles amphotericin B and micafungin only after definitive diagnosis. ${ }^{1}$ Topical administration of amphotericin B and nystatin is used most commonly to treat oral candidiasis and denture stomatitis. ${ }^{2}$ Azoles such as fluconazole and ketoconazole are employed for systemic antifungal treatment, of which fluconazole is most commonly used because of its broad-spectrum antifungal activity and safety. ${ }^{4}$ These pharmacological agents are not used for prophylactic purposes. The prophylactic measure used is oral care. ${ }^{1}$ Various attempts have been made to inhibit candidal colonization and adhesion on the denture surface by using a wide range of antifungal agents and different modalities.

\section{Denture Cleansers}

Dentures can be cleaned chemically, mechanically, or both. Mechanical cleaning like brushing can be effective if carried out properly, but it may lead to abrasion of the denture surface if used overenthusiastically or incorrectly. The mechanical methods are also difficult for patients with impaired manual dexterity. The chemical methods are proven to be more effective than mechanical methods. The chemical method is effective and simple to use in reducing the formation of candidal biofilm. Hence, the chemical methods are the common alternative for mechanical cleaning. ${ }^{5}$

\section{Commercially Available Denture Cleansers}

The ideal disinfectant should maintain the denture cleanly without altering the denture structure. So, the dental cleanser used must be non-deteriorative to denture and safe to use. Certain cleansers may have a harmful effect on the denture properties; hence, a study was conducted to evaluate the surface roughness and candidal attachment on heat cure and light cure dentures bases using Corega, Fittydent, and Lacalut denture cleansers. It was concluded from the study that attachment of Candida albicans was reduced on immersion in dental cleansers, while there was no effect on the surface roughness of the denture. ${ }^{10}$

The chemical cleansers usually include alkaline peroxide, sodium hypochlorite, enzymes, acid, and neutral enzymatic peroxide solutions. The preferred denture cleansers are effervescent tablets that yield an alkaline peroxide solution on dilution with water. These are preferred as they cleanse the dentures effectively without damaging the surface. But the biofilm layer cannot be fully removed from the denture base surface, and some viable cells remain on the surface. Three important factors that influence the cleansing are resin type with the physiochemical features, the concentration of the cleanser, and the type of cleanser.
Three cleansers Corega, Fittydent, and Polident 3 minute were tested at different concentrations on different materials like heatpolymerized acrylic resin, high-impact heat-polymerized acrylic resin, and polyamide thermoplastic resin. It was found that Polident 3 minute and Corega were suitable for all types of resins, whereas Fittydent was suitable for polyamide thermoplastic resin. ${ }^{11}$ Another study compared the effectiveness of Klorhex and Fittydent against colonization of Candida species. It was found that both Klorhex and Fittydent had a preventive effect on colonization of Candida species present on the palatal mucosa, on the surface of the denture, and on acrylic strips tested in vitro. In palatal mucosa, the colonies reduced from $62.2 \%$ to $51.1 \%$, and on the dentures, the colonies were reduced from $82.2 \%$ to $68.8 \%$. The adhesion of the Candida strains from the acrylic strips was initially found to be 75 cells/strip and was reduced to 37.5 cells/strip in Klorhex and 15 cells/strip in Fittydent. $^{12}$

A study analyzed the nocturnal storage state on plaque growth and composition on acrylic dentures in the absence of mechanical cleansing. The preservations were done in tap water, dry or tap water with alkaline peroxide effervescent tablets. It was found that effervescent tablets significantly reduced the bacterial count, denture candidal biofilm mass, and pathogenicity when compared to dry and water preservation. ${ }^{13}$

\section{Other Denture Cleansers}

Some patients tend to use household denture cleansers like vinegar, soda, salt, and bleach because of their low cost and ease of availability. A study was conducted to assess the efficiency of household denture cleansers and commercially available denture cleansers against Candida albicans. It was inferred from the study that commercial dental cleansers like Fittydent and Clinsodent were more effective than household denture cleansers like vinegar in the removal of Candida albicans. Among the commercially available dentures observed in the study, it was found that Fittydent was slightly effective than Clinsodent, but it was not statistically significant. ${ }^{5}$

For the elderly patients, cost-effective and easily available denture cleansers are an important factor. Certain plant extracts have recently been proved as an alternative for synthetic medicines and could be used effectively as safe therapeutic agents. Certain extracts like thyme essential oil have good antifungal activity against Candida albicans and can also be used as a disinfectant to prevent denture stomatitis. A study was conducted between plant extracts like thyme essential oil and Nigella sativa and denture cleansers like Fittydent and CD Clean for the prevention of Candida albicans growth on soft denture liners. It was found that Fittydent was most effective against Candida, followed by thyme essential oil, Nigella sativa, and CD Clean. ${ }^{14}$ Everyday removal of bacterial and candidal biofilm is important to reduce denture stomatitis and to produce good oral and general health.

\section{Mouthwashes as Denture Cleansers}

Recently, mouthwashes have gained effectiveness for cleansing dentures. In general, anticaries and mouth refreshing mouthwashes are used. A study was performed to evaluate the efficacy of two mouthwashes against three alkaline peroxide tablets, namely Polident, Efferdent, and Fittydent, against Candida albicans in patients with denture stomatitis. The study concluded that mouthwashes significantly reduced microorganisms on dentures, whereas Fittydent was found to be effective among the denture cleansers after 60 minute of treatment. ${ }^{15}$ Another similar study 
showed that the highest removal activity against Candida albicans was by mouthwashes. It also states that further studies are essential to determine whether daily usage of mouth rinse can reduce the prevalence of patients having denture stomatitis. ${ }^{16}$

\section{Marine Algae and Seaweeds}

Seaweeds are abundantly available in nature and are renewable sources found in the marine system. ${ }^{17}$ The marine macroalgae are good sources of structurally new and biologically active secondary metabolites. Recently, there is an increasing demand of obtaining therapeutic drugs from natural products and seaweed. ${ }^{18}$ Seaweeds are natural resources found in the coastal region between low and high tide range and some areas of subtidal regions. In these regions, up to a depth of $0.01 \%$ polysynthetic light is available. This is used for food and drug discoveries. ${ }^{6}$ The seaweed is useful to man in many ways like food, fodder, medicine as a fertilizer and is an economically valuable resource. ${ }^{19}$ The seaweeds are rich in amino acid and bioplant enhancers and are used as industrial raw materials, cosmetics, and food and for therapeutic purposes. ${ }^{20}$ The seaweeds can be classified into three types based on the type of pigment they have: green (Chlorophyta), red (Rhodophyta), and brown (Heterokontophyta) seaweeds. ${ }^{6}$ Red and brown algae are used as human food sources. ${ }^{21}$ The brown algae are consumed as food as they are rich in vitamins, minerals, polysaccharides, and polyunsaturated fatty acids. It has a wide spectrum of biological activity like antiviral, antibacterial, antioxidant, and antifungal against human pathogens. Special attention has been given to antifungal activities as there is a high mortality rate against fungal infections in human populations. ${ }^{18}$

\section{Turbinaria conoides}

Turbinaria conoides is also known as agar-agar lesong. ${ }^{22}$ Turbinaria conoides belongs to the family Sargassaceae. It is a type of brown algae. ${ }^{23}$ It has an erect thallus which is tall $(13 \mathrm{~cm})$, dark brown, and attached to substrate with a branched holdfast. Turbinaria has been used to cure fever for children, as an insect repellent, as a fertilizer, and as an antibacterial agent. The cyclohexane extract of Turbinaria conoides has found to have good antifungal activities. Two new antifungal steroids 3,6,17-trihydroxy-stigamasta4,7,24(28)-triene and 14,15,18,20-diepoxyturbinarin together were called as fucosterol and were isolated from the cyclohexane extract of Turbinaria conoides. ${ }^{22}$

The antimicrobial potential of the brown seaweed Turbinaria conoides was tested and found that methanol, ethanol, and ethyl acetate extract showed maximum inhibition against Candida albicans. It was also found to have associated antibacterial property. $^{21}$

The antifungal activity of Turbinaria conoides collected from Mandapam coast of Tamil Nadu was assessed at different concentrations under different extracts. The extracts used were hexane, chloroform, ethanol, clotrimazole, and ketoconazole. Antifungal activity was tested against Candida albicans, Candida parapsilosis, Aspergillus fumigatus, and Fusarium species. The hexane, chloroform, and ethanolic extract had a well profound inhibitory activity against Candida albicans and Candida parapsilosis. The maximum inhibitory activity against Candida was found in hexane extracts at $2000 \mu \mathrm{g} / \mathrm{mL}$. $^{24}$

Future scope lies in identifying the principal compound responsible for antifungal activity against the fungal pathogens, especially those causing diseases to humans. ${ }^{24}$

\section{SUMMARY}

One of the major problems faced by denture wearers and geriatric population is denture stomatitis, which is mainly caused by Candida albicans. Hence, it is the primary pathogen targeted in the formulation of various dental cleansers. Various attempts have been made to inhibit candidal colonization and adhesion on the denture surface by using a wide range of antifungal agents and different modalities. The commercially available denture cleansers are proven to be effective in reducing the colonization of Candida albicans. However, novel biological antifungal compounds are being explored. One such promising option is Turbinaria conoides, the extract of which has proven to have anticandidal and antifungal properties. More research has to be employed in identifying the principal compound responsible for producing antifungal properties against the fungal pathogens.

\section{References}

1. Kamikawa Y, Hirabayashi D, Nagayama T, Fujisaki J, Hamada T, Sakamoto $\mathrm{R}$, et al. In vitro antifungal activity against oral Candida species using a denture base coated with silver nanoparticles. J Nanomat 2014;2014:48. DOI: 10.1155/2014/780410.

2. AL-Janabi AA, Abdulkareem MM. Elevation of the resistance of heatcured acrylic denture base resin against biofilm-forming Candida albicans by incorporating amphotericin B or clotrimazole. J Oral Res Rev 2018;10(2):51.

3. Maldonado K, Xu D, Wang Y, Zhang JF, Hamdan S, Wen ZT, et al. Mechanical and physical properties of experimental antifungal denture base resins. Oral Health Dent Stud 2018;1(1):5. DOI: 10.31532/ OralHealthDentStud.1.1.005.

4. Chincholikar S, Sridevi J, Kalavathy N, Singh S, Kapoor A, Saumya S. Comparative evaluation of two antifungal agents incorporated in auto polymerising denture base resin, heat polymerising denture base resin and permanent silicone soft liner-an in vitro study. J Clin Diagnos Res 2019;13(1):49-54.

5. Kumar MN, Thippeswamy HM, Swamy KR, Gujjari AK. Efficacy of commercial and household denture cleansers against Candida albicans adherent to acrylic denture base resin: an in vitro study. Indian J Dent Res 2012;23(1):39. DOI: 10.4103/0970-9290.99036.

6. Manigandan M. In vitro antifungal activity of certain seaweeds collected from Mandapam coast, Tamilnadu, India. Int J Adv Res Biol Sci 2014;1(7):557-559.

7. Park SE, Blissett R, Susarla SM, Weber HP. Candida albicans adherence to surface-modified denture resin surfaces. J Prosthodont 2008;17(5):365-369. DOI: 10.1111/j.1532-849X.2007.00292.x.

8. Ariamanesh H, Tamizi N, Yazdinezhad A, Salah S, Motamed N, Amanloo $S$. The effectiveness of nigella sativa alcoholic extract on the inhibition of Candida albicans colonization and formation of plaque on acrylic denture plates: an in vitro study. J Dent 2019;20(3):171-177. DOI: 10.30476/DENTJODS.2019.44911.

9. Nett JE, Marchillo K, Spiegel CA, Andes DR. Development and validation of an in vivo Candida albicans biofilm denture model. Infect Immun 2010;78(9):3650-3659. DOI: 10.1128/IAI. 00480-10.

10. Aziz HK. Evaluation of surface roughness and Candida albicans attachment on light cured and heat cured acrylic denture base resin using Corega, Fittydent and Lacalut denture cleansers. Mustans Dent J 2015;12(1):53-65.

11. Hayran Y, Sarikaya I, Aydin A, Tekin YH. Determination of the effective anticandidal concentration of denture cleanser tablets on some denture base resins. J Appl Oral Sci 2018;26:e20170077. DOI: 10.1590/1678-7757-2017-0077.

12. Nalbant AD, Kalkanci A, Filiz B, Kustimur S. Effectiveness of different cleaning agents against the colonization of Candida spp and the in vitro detection of the adherence of these yeast cells to denture 
acrylic surfaces. Yonsei Med J 2008;49(4):647-654. DOI: 10.3349/ ymj.2008.49.4.647.

13. Duyck J, Vandamme K, Muller P, Teughels W. Overnight storage of removable dentures in alkaline peroxide-based tablets affects biofilm mass and composition. J Dent 2013;41(12):1281-1289. DOI: 10.1016/ j.jdent.2013.08.002.

14. Khan MA, Dhaded S, Joshi S. Commercial and plant extract denture cleansers in prevention of Candida albicans growth on soft denture reliner: in vitro study. J Clin Diagnos Res: JCDR 2016;10(2):ZC42. DOI: 10.7860/JCDR/2016/12558.7228.

15. Uludamar A, Özkan YK, Kadir T, Ceyhan I. In vivo efficacy of alkaline peroxide tablets and mouthwashes on Candida albicans in patients with denture stomatitis. J Appl Oral Sci 2010;18(3):291-296. DOI: 10.1590/s1678-77572010000300017.

16. Işeri U, Uludamar A, Ozkan YK. Effectiveness of different cleaning agents on the adherence of Candida albicans to acrylic denture base resin. Gerodontology 2011;28(4):271-276. DOI: 10.1111/j.17412358.2010.00379.x.

17. Rajeshkumar S, Malarkodi C, Paulkumar K, Vanaja M, Gnanajobitha G, Annadurai $G$. Algae mediated green fabrication of silver nanoparticles and examination of its antifungal activity against clinical pathogens. Int J Metals 2014;2014:692643. DOI: 10.1155/2014/692643.
18. Pandithurai M, Subbiah M, Vajiravelu S, Selvan T. Antifungal activity of various solvent extracts of marine brown alga Spatoglossum asperum. Int J Pharm Chem 2015;5:277-280.

19. Selvaraju P, Vijayakumar A. Evaluation of antifungal activity of seaweed extract (Turbinaria conoides) against Fusarium oxysporum. J App Nat Sci 2016;8(1):60-62. DOI: 10.31018/jans.v8i1.747.

20. Selvaraju P, Vijayakumar A. Evaluation of antifungal activity of seaweed extract (Turbinaria conoides) against Pythium aphanidermatum (edson) fitzp by ameer junaithal begum. Life Sci Leaf 2015;63:162-168.

21. Manivannan $\mathrm{K}$, Anantharaman $\mathrm{P}$, Balasubramanian T. Antimicrobial potential of selected brown seaweeds from vedalai coastal waters, Gulf of Mannar. Asian Pac J Trop Biomed 2011;1(2):114-120. DOI: 10.1016/S2221-1691(11)60007-5.

22. Kumar SS, Kumar Y, Khan MS, Gupta V. New antifungal steroids from Turbinaria conoides (J. Agardh) Kutzing. Nat Prod Res 2010;24(15):1481-1487. DOI: 10.1080/14786410903245233.

23. Kumar S, Kumar Y, Khan M, Anbu J, Sam K. Acute toxicity study and antipyretic effect of the brown alga Turbinaria conoides (J. agardh) Kuetz. Afr J Tradit Complement Altern Med 2009;6(3):233-240. DOI: 10.4314/ajtcam.v6i3.57159.

24. Shibu A, Dhanam S. In vitro antifungal activity of Turbinaria conoides collected from Mandapam coast, Tamil Nadu, India. J Experiment Sci 2016. 27-30. DOI: 10.25081/jes.2016.v7.3057. 